\title{
Influence of population and general practice characteristics on prescribing of minor tranquilisers in primary care
}

Andrew C. WAGNER, Mark HANN, Darren M. ASHCROFT. Received (first version): $12-$ Feb-2010 Accepted: 25-Aug-2010

\begin{abstract}
${ }^{*}$
Prevalence of generalised anxiety disorders is widespread in Great Britain. Previous small-scale research has shown variations in minor tranquiliser prescribing, identifying several potential predictors of prescribing volume.

Objective: This study aimed to investigate the relationship between general practice minor tranquiliser prescribing rates and practice population and general practice characteristics for all general practices in England.

Methods: Multiple regression analysis of minor tranquiliser prescribing volumes during 2004/2005 for 8,291 English general practices with general practice and population variables obtained from the General Medical Services (GMS) statistics, Quality and Outcomes Framework (QOF), 2001 Census and 2004 Index of Multiple Deprivation (IMD). Results: The highest rates of minor tranquiliser prescribing were in areas with the greatest local deprivation while general practices situated in areas with larger proportions of residents of black ethnic origin had lower rates of prescribing. Other predictors of increased prescribing were general practices with older general practitioners and general practices with older registered practice populations.

Conclusion: Our findings show that there is wide variation of minor tranquilisers prescribing across England which has implications regarding access to treatment and inequity of service provision. Future research should determine the barriers to equitable prescribing amongst general practices serving larger populations of black ethnic origin.
\end{abstract}

Keywords: Tranquilizing Agents. Drug Prescriptions. Drug Utilization. Healthcare Disparities. United Kingdom.

\section{INFLUENCIA DE LAS CARACTERÍSTICAS DE LA POBLACIÓN Y DE LOS MÉDICOS GENERALES EN LA PRESCRIPCIÓN DE TRANQUILIZANTES MENORES}

\begin{abstract}
RESUMEN
La prevalencia de desordenes de ansiedad generalizada está en aumento en Gran Bretaña. Previos estudios a pequeña escala han mostrado variaciones en la prescripción de tranquilizantes menores, identificando varios predictores potenciales del volumen de prescripción. Objetivo: Este estudio trató de investigar la relación entre la prescripción por médicos generales de tranquilizantes menores y las características de los médicos generales en toda Inglaterra.

Métodos: Regresión múltiple de los volúmenes de prescripción de tranquilizantes menores durante 2004/2005 en las 8.291 clínicas de medicina general de Inglaterra con variables de la clínica, y de la población obtenidas de la estadística de los Servicios de Medicina General, Quality and Outcomes Framework, censo de 2001 y del Índice Múltiple de Pobreza de 2004.

Resultados: Las tasas más altas de prescripción de tranquilizantes menores estaban en áreas con mayor pobreza, mientras que los médicos generales situados en áreas de mayor población de ciudadanos de raza negra tenían las tasas más bajas de prescripción. Otros predictores de aumento de prescripción eran clínicas con médicos de más edad y clínicas con población registrada de más edad. Conclusión: Nuestros hallazgos muestran que hay una gran variación en la prescripción de tranquilizantes menores en Inglaterra lo que tienen implicaciones en relación al acceso al tratamiento y a la inequidad de la provisión del servicio.

Investigaciones posteriores deberían determinar las barreras a una prescripción equitativa entre los médicos generales que sirven a las mayores poblaciones de origen ético negro.
\end{abstract}

Palabras clave: Tranquilizantes. Prescripción de medicamentos. Utilización de medicamentos. Disparidades en salud. Reino Unido.

\section{INTRODUCTION}

Generalised anxiety disorders are estimated to affect 44 out of 1000 adults in Great Britain. Evidence suggests that certain population groups 
are at greater risk, with deprived communities experiencing higher prevalence of treated anxiety. ${ }^{1-3}$ Age and gender also predict higher prevalence with sharply increasing minor tranquiliser ${ }^{\dagger}$ prescribing rates in the elderly, particularly amongst older females. ${ }^{1,4}$ Previous studies have indicated that extent of local deprivation and population socioeconomic characteristics may influence general practice minor tranquiliser prescribing and prescribing for other conditions, as well as affecting appropriate service provision. However population factors do not consistently predict higher prescribing and there is evidence of lower prescribing rates across a range of health conditions in some deprived and ethnically diverse areas. ${ }^{5-8}$

Variable prescribing rates for heart disease, relative to local need, have been associated with aspects of primary care quality and differences in health care equity. ${ }^{9,10}$ In 2003/4, as part of a range of health inequalities monitoring exercises, the English Commission for Health Improvement (CHI) published data from a national performance assessment. ${ }^{11}$ The exercise included a prescribing indicator comparing rates for drugs acting on benzodiazepine receptors (WHO ATC N05C; BNF 4.1.1) amongst the 302 Primary Care Organisations (PCOs) which are the main local providers of primary health care services. The survey revealed extensive disparities amongst PCOs (mean $=8.78$ ADQs per STAR-PU; range=3.90-15.52; $S D=2.76$ ) (10). Using the $\mathrm{CHI}$ performance thresholds, benzodiazepine prescribing rates for 31 PCOs $(10 \%)$ were classified as inappropriately high and performance considered "significantly below average". Of this group, $22(71 \%)$ were included in the 88 "spearhead" PCOs, identified by the Department of Health as those areas experiencing the greatest health deprivation, characterised by rates of high material deprivation, mortality and numbers of life years lost. ${ }^{12}$ Conversely, out of the 12 lowest benzodiazepine prescribing PCOs, five $(42 \%)$ were "spearhead" PCOs, all located within the London area.

Several small scale studies exploring reasons for variations in minor tranquiliser prescribing by general practices have been performed in England. These studies outlined below, have examined potential associations between prescribing rates and general practice characteristics and local population demographics. Significant differences in anxiolytics, hypnotics and antidepressants prescribing rates were found within a group of 61 general practices. ${ }^{13}$ The strength of associations with prescribing and practice or population characteristics were limited in this study, with the findings only suggesting that temporary residential status and females aged 65 years or over predicting higher prescribing rates. ${ }^{13}$ Other studies have established stronger relationships with practice

† Minor tranquilisers are defined as those categorised by the World Health Organisation (WHO) Anatomical Therapeutic Chemical (ATC) classifications N05B: Anxiolytics; N05C: Hypnotics and Sedatives, or by the British National Formulary (BNF), Chapter 4.1: anxiolytics, hypnotics and barbiturates. characteristics. Benzodiazepine prescribing in a sample of 350 general practices was lower in general practices providing general practitioner (GP) training, that were multiple partner practices or located in more affluent areas. ${ }^{14}$ A study of 78 general practices found significant correlations between local extent of morbidity and antidepressant prescribing. ${ }^{15}$ The ratio of numbers of general practitioners per head of population and proportion of the population not having English as a first language were found to be predictors of variation for anxiety and depression in 39 relatively deprived neighbourhoods. ${ }^{16}$ Illustrative of the difficulties in interpreting predictors of variation, an east London based study found that higher prevalence of Asian ethnicity in the local community accounted for significantly lower rates of anxiolytic prescribing. The authors commented on the uncertainty of whether this was caused by lower disease prevalence, general practitioner prescribing behaviour or difficulties with screening for anxiety. ${ }^{6}$ The divergence of predictors gleaned from these studies could stem from the geographically diverse settings of the research and their particular demographic and socioeconomic profiles.

The aim of this study is to explore the relationship between minor tranquiliser prescribing rates and socioeconomic, demographic and general practice characteristics using data which includes all general practices in England. The study uses small area population data, linked to each general practice, from a variety of national datasets.

\section{METHODS}

\section{Prescribing data}

Weighted volumes of minor tranquilisers (WHO ATC classifications N05B, N05C / BNF Chapter 4.1) prescribed were used as the general practice level outcome measure. ${ }^{17}$ In 2004, anxiolytics constituted $62 \%$ of all dispensed minor tranquilisers, while hypnotics accounted for $38 \%$ and barbiturates $0.2 \%{ }^{18}$ Prescribing volume data for the period April 2004 to March 2005, were provided by the Prescription Pricing Authority, derived from the national Prescribing Analysis and Cost (PACT) database. Specific Therapeutic group Age-sex Related Prescribing Units (STAR-PU) weightings were applied to compare prescribing volumes for individual general practice. This measure accounts for the age, gender and temporary residence profile of each general practice's patient register, providing a numerical weighted compensation for differences in practice population age and sex proportions. ${ }^{19}$ Prescription volumes were measured using average daily quantities (ADQ) which are analytical units for comparing prescribing activity amongst the major drug groups in England. ${ }^{20}$ ADQ per STAR-PU are extensively used in England by administrative and governing health organisations to monitor appropriate general practice prescribing and comparative costs, within therapeutic groups. ADQs were adopted in recognition of the differences in prescribing patterns by English general practices compared to the WHO classification of Daily Defined Doses (DDDs) which are based on general 
international prescribing habits, consequently not accurately reflecting activity in England.

\section{Population characteristics}

A range of potential population-based explanatory variables, derived from several sources, was constructed to test the extent to which prescribing activity could be explained by these. Population characteristics were attributed to each general practice using the weighted local Index of Multiple Deprivation (IMD) and demographic features obtained from the Office of National Statistics 2001 Census. ${ }^{21}$ Data were linked by practice postcode, using lower level super output areas (SOA) which are small area geographical units of approximately 1500 residents. SOAs allow measurement of local concentration, extent or weighted averages of population characteristics.

The IMD measure combines seven dimensions of deprivation: income deprivation; employment deprivation; health deprivation and disability; education, skills and training deprivation; barriers to housing and services; living environment deprivation; and crime and living environment. The indicator provides a neighbourhood deprivation score for the practice location as home address specific data for registered patients were not available nationally. The IMD has been used frequently as an indicator for tests of association between local deprivation and equity of primary care service provision. ${ }^{22-24}$

Potential determinants of population health status were obtained from the 2001 Office of National Statistics Census, aggregated to SOA level and linked to general practices, attributing local population estimates of:

- ethnic origin

- housing tenure

- limiting long-term illness

- lone parent status

- National Statistics - Socio-economic Classification (NS-SeC)

Previous research has shown association between ethnic composition of the population and broad patterns prescribing rates in primary care in England. ${ }^{8}$ Housing tenure can be used as a socioeconomic marker of health status which may, in itself, contribute to improving or worsening health. ${ }^{25}$ Households with limiting long-term illness, is a self-reported measure allowing investigation of differences in local health need. ${ }^{26}$ Lone parents, $95 \%$ of whom were female, have been shown to experience significantly poorer health. ${ }^{27}$ The NS$\mathrm{SeC}$ uses employment occupation type or status as a method of classifying social position. ${ }^{28,29}$ There are eight classes: large employers and higher managerial and professional occupations; lower managerial and professional occupations; intermediate occupations; lower supervisory and technical occupations; semi-routine occupations; routine occupations; never worked and long-term unemployed.

\section{General practice characteristics}

Practice characteristics indicators were obtained from the 2005 General Medical Services Statistics, extracted from the National Primary Care Database. ${ }^{30}$ Proportions of registered patients aged 75 or over on each practice patient register were used as a proxy measure for intensity of general practice workload, with older people accounting for a relatively large proportion of general practitioner consultations and prescribing. ${ }^{31,32}$ The data included general practice list size per full time equivalent general practitioner; single-handed GP status; training practice status; practice incentive and payment circumstance indicated by Personal Medical Services (PMS) status. Over a third $(35.5 \%)$ of practices were contracted under the Personal Medical Services scheme in 2004. Training practices are accredited centres for training GP specialty registrars, medical students and returning career-break GPs.

Quality and Outcomes Framework (QOF) data relating to general practice disease prevalence were obtained from the NHS Information Centre for the period April 2004 to March 2005. ${ }^{33}$ The QOF system, introduced through the 2004 General Medical Services (GMS) contract, provides financial incentives to achieve a series of clinical, organisational and patient experience activity targets. The clinical element covers management aspects of 11 chronic illnesses: coronary heart disease; mental health; stroke; hypertension; diabetes; chronic obstructive pulmonary disease; hyperthyroid; cancer; left ventricular dysfunction; asthma and epilepsy.

The QOF exercise includes maintenance of disease registers by practices, allowing calculation of practice level raw prevalence rates. Prevalence rates are calculated by dividing practice disease registers by numbers of patients on the practice patient list. Though open to some interpretation by GPs for inclusion on the register, mental health registers contain those people with severe or longterm mental health problems who have agreed to regular follow-up consultation. ${ }^{34}$ A further QOF indicator, achievement of 10 minutes length of consultation, was also included as an indicator of practice management quality.

\section{Statistical methods}

A dataset was developed incorporating prescribing volumes, practice characteristics, QOF data and attributed population characteristics. Differences in extraction dates for the 2004 GMS and 2004-05 QOF datasets and data validation reduced the number of practices eligible for inclusion in the study from 8576 to 8291 (96.7\%). The differences in numbers were caused by practices opening and closing over the intervening period or being excluded from the study due to recorded list sizes of fewer than 750 registered patients. Twelve further practices were excluded on the grounds that their prescribing rates were zero. The outcome variable in this study was the ADQ per 1,000 STAR-PUs of prescribed minor tranquillizers for each general practice. 
Data analysis was performed using Stata (version 9.2). Many of the potential independent variables were highly co-linear and many were not linearly related to the outcome variable, due to very high skewness. Therefore, we used only a subset of the variables, selected so as to avoid co-linearity. These variables were then categorised (Table 1). Multiple regressions were performed to determine which variables were most strongly associated with the prescribing of minor tranquillisers. We used the logarithm of the prescribing rate, due to the highly skewed distribution of the actual prescribing rates: a not insignificant number of practices had very high prescribing volumes. As there was no wider reference population to which the data could be generalised, formal significance testing is highly contentious; as such, we concentrate on the general interpretation of the model parameters rather than statistical significance. In such a large dataset, all associations are likely to be significant in any case.

\section{RESULTS}

Details of the distribution of the variables used in the multiple regression analysis are shown in Table 1. There was wide variation in minor tranquiliser prescribing, with a median prescribed volume of 9887.2 ADQs per 1000 STAR-PUs (Inter-Quartile Range: 6794.2 to 14132.5 ; range: 109.2 to 134133.5)

Table 2 summarises the regression results. The coefficient $10 \beta$ - the inverse ('back transformation') of the logarithm - expresses the impact that each parameter has on the 'original' practice prescribing rate, adjusting for other factors. For example, being located in a heavily deprived area (IMD>40) increases a general practice's prescribing rate by a factor of 1.532 compared with being located in the most affluent area (IMD $\leq 10)$.

The coefficient of $10 \beta$ for the baseline category of each categorical variable is 1 . The model coefficients show that general practices located in increasingly deprived areas have increasingly higher prescribing rates for minor tranquillisers. This is also true for general practices whose GPs are, on average, older, that have an increasingly greater proportion of patients aged 75 and over, and whose patients have, independently, a greater prevalence of epilepsy and mental health problems. In contrast, practices with an increasingly greater proportion of black patients have increasingly lower prescribing rates for minor tranquillisers: however, this is not true of practices with increasing proportions of South Asian patients where prescribing rates are more constant. Training practices have lower prescribing rates than non-training practices. There is little difference between the prescribing rates of single-handed and multi-handed practices.

\section{DISCUSSION}

This study provides a national perspective on variations in minor tranquiliser prescribing by GPs, using data from a range of routinely collected datasets for $96.7 \%$ of English general practices. Previous small-scale studies have established a variety of predictive associations, often with results related and bound to the distinctive characteristics of those study areas. Using a national approach to general practice-level study does, however, encounter some potential constraints. Bias may be introduced by ascribing inaccurate small area population factors to general practices. Patients living in an area attributed to the practice may be registered at a practice elsewhere. A further limitation was the lack of availability of individual patient-level data. The study allocated area-based population characteristics to general practices on the basis of their geographical locations. Use of proxy data could possibly lead to the ecological fallacy whereby general characteristics attributed to a population group may be attributed wrongly to individuals within the group. For example, ethnic origin data in this study were aggregated from more finely distinct ethnic categories, into broader groups of South Asian, black, mixed and white, which could obscure some of the cultural and health behavioural differences within those groups. It has been argued that an ecological level study can be appropriate for between population comparisons and that small area indicators such as the IMD score are valid proxy measures for general practice populations. $^{35,36}$

The results from this study suggest extensive variation in minor tranquiliser prescribing by general practitioners. More minor tranquilisers were prescribed by general practices situated in areas of higher local deprivation. Higher prescribing was also associated with practices with proportionally older registered. Higher prevalence of epilepsy also predicted higher rates of minor tranquilising prescribing. Practices in areas with higher proportions of residents from black ethnic groups showed significantly negative prescribing rates. Previous research investigating a range of health conditions, revealed lower prescribing volumes in areas with higher ethnic minority populations. ${ }^{8}$ The reasons for lower prescribing were not clear from the data, however, possible influences of doctorpatient relationships and the broader social context of health service bias to the wider white population were postulated. Further study may reveal whether this variation is caused by lower reported symptoms of anxiety and depression for this population group or due to unequal access to treatments.

General practices with older general practitioners were positively associated with higher minor tranquiliser prescribing. There is scope for further research concerning general practitioner demographics and approaches to appropriate minor tranquiliser prescribing. Previous qualitative research of differences in general practitioners' views and behaviour concerning medical risk and benzodiazepine prescribing, highlighted improvements in accepted practice. ${ }^{37}$ However, the study showed that there was not uniform aversion to benzodiazepine prescribing, despite their unfavoured status, with differences in attitude to patient risk. Other primary care research has reported differences in antidepressant drug knowledge and prescribing behaviour between older and younger general practitioners, with older 
general practitioners having less confidence in treating late-life depression and being more aware of the need for further psychiatric training. ${ }^{38,39}$ Previous studies have investigated patient and physician barriers to recognition, diagnosis and effective treatment of depression. There is evidence of patient unwillingness to admit presence of depression, the nature of depression, along with difficulties faced by general practitioners in recognising and treating depression in culturally diverse populations. ${ }^{40,41}$

Our study revealed a clear association between epilepsy and increased minor tranquiliser prescribing. Previous primary care based research found association between depression prevalence and complaints of side-effects of antiepileptic medication and with recent episodes of epileptic seizures. ${ }^{42}$ The study highlighted implications for care management and reduction of depression and epileptic co-morbidity, particularly through screening for and identifying adverse reactions to antiepileptic drugs. Further work could establish whether increased care management of epilepsy might reduce prescribing for associated acute anxiety disorders.

\section{CONCLUSIONS}

The findings in this study have implications about the appropriateness of effective care for people with generalised anxiety disorders in terms of prescribing. The associated group of prescribing variation predictors indicate a complex interplay of prescribing behaviour and geographically based socio-demographic factors influencing clinical care. In light of the distinct negative associations of antidepressant prescribing and effects of patient ethnicity, further work is needed to explore reasons for these prescribing differences and related issues of prescribing management. Further study is warranted to determine the barriers to provision of appropriate minor tranquiliser prescribing amongst general practices serving larger populations of black ethnic origin.

\section{ACKNOWLEDGEMENT}

We are grateful to the NHS Prescription Services for provision of general practice prescribing data and thank the reviewer for valuable suggestions for the paper.

\section{CONFLICT OF INTEREST}

The authors have no conflicts of interest including, but not limited to, consulting fees, paid expert testimony, employment, grants, honoraria, royalties, stocks, or other financial or material gain that may involve the subject matter of the manuscript. This investigation was fully funded by the University of Manchester School of Pharmacy and Pharmaceutical Sciences.

\section{References}

1. Psychiatric morbidity among adults living in private households. (2001) London: Office of National Statistics.

2. Weich S, Lewis G. Material standard of living, social class, and the prevalence of the common mental disorders in Great Britain. J Epidemiol Community Health. 1998;52(1):8-14.

3. Ostler K, Thompson C, Kinmonth AL, Peveler RC, Stevens L, Stevens A. Influence of socio-economic deprivation on the prevalence and outcome of depression in primary care: the Hampshire Depression Project. Br J Psychiatry. 2001;178(1):12-17

4. Key health statistics from general practice 1998. (2000) London: Office of National Statistics. Report No.: 2.

5. Hull SA, Aquino $P$, Cotter $S$. Explaining variation in antidepressant prescribing rates in east London: a cross sectional study. Fam Pract. 2005;22(1):37-42.

6. Hull SA, Cornwell J, Harvey C, Eldridge S, Bare PO. Prescribing rates for psychotropic medication amongst east London general practices: low rates where Asian populations are greatest. Fam Pract. 2001;18(2):167-173.

7. Ashworth M, Lloyd D, Smith RS, Wagner A, Rowlands G. Social deprivation and statin prescribing: a cross-sectional analysis using data from the new UK general practitioner 'Quality and Outcomes Framework'. J Public Health (Oxf). 2007 Mar;29(1):40-47.

8. Hann M, Cantrill J, Baker D, Gill P. Prescribing patterns in high-need Health Authority populations: how does an ethnically mixed composition affect volume and cost? J Clin Pharm Ther. 2004;29(6):537-546

9. Ward PR, Noyce PR, St Leger AS. Are GP practice prescribing rates for coronary heart disease drugs equitable? A cross sectional analysis in four primary care trusts in England. J Epidemiol Community Health. 2004 Feb;58(2):89-96.

10. Packham C, Robinson J, Morris J, Richards C, Marks P, Gray D. Statin prescribing in Nottingham general practices: a cross-sectional study. J Public Health Med. 1999;21(1):60-64.

11. Commission for Health Improvement. Commission for Health Improvement website. Available at: http://www.chi.nhs.uk/Ratings/Trust/Indicator/IndicatorDescriptionShort.asp? Indicatorld=4553, accessed on 21 February 2008.

12. Department of Health Website. Available at: http://www.dh.gov.uk/en/Publicationsandstatistics/Pressreleases/DH_4095409, accessed on 10 January 2008.

13. Pharoah PD, Melzer D. Variation in prescribing of hypnotics, anxiolytics and antidepressants between 61 general practices. Br J Gen Pract. 1995;45(400):595-599.

14. Wilson RP, Hatcher J, Barton S, Walley T. The influence of practice characteristics on the prescribing of benzodiazepines and appetite suppressant drugs. Pharmacoepidemiol Drug Saf. 1998;7(4):243-251.

15. Mackenzie IF, Buckingham K, Wankowski JM, Wilcock M. Morbidity, deprivation, and antidepressant prescribing in general practice. Br J Gen Pract. 1999;49(448):884-886. 
16. Goyder E, Dibben C, Grimsley M, Peters J, Blank L, Ellis E. Variation in prescribing for anxiety and depression: a reflection of health inequalities, cultural differences or variations in access to care? Int J Equity Health. 2006;5:4.

17. Joint Formulary Committee. British National Formulary 54. British Medical Association and the Royal Pharmaceutical Society of Great Britain.

18. NHS Prescription Pricing Division website. Available at: http://www.ppa.org.uk, accessed on: 10 November 2007

19. Lloyd DC, Harris CM, Roberts DJ. Specific therapeutic group age-sex related prescribing units (STAR-PUs): weightings for analysing general practices' prescribing in England. BMJ. 1995;311(7011):991-994.

20. Walley T, Roberts D. Average daily quantities: a tool for measuring prescribing volume in England. Pharmacoepidemiol Drug Saf. 2000;9(1):55-58.

21. The English Indices of Deprivation 2004. (2005) London: Office of the Deputy Prime Minister.

22. Strong M, Maheswaran R, Pearson T, Fryers P. A method for modelling GP practice level deprivation scores using GIS Int J Health Geogr. 2007;6:38.

23. Adams J, White M. Socio-economic deprivation is associated with increased proximity to general practices in England: an ecological analysis. J Public Health (Oxf). 2005;27(1):80-81.

24. Pritchard C, de Verteuil B. Application of health equity audit to health visiting. Community Pract. 2007;80(5):38-41.

25. Macintyre S, Ellaway A, Der G, Ford G, Hunt K. Do housing tenure and car access predict health because they are simply markers of income or self esteem? A Scottish study. J Epidemiol Community Health. 1998;52(10):657-664.

26. Bentham G. Limiting long-term illness and its associations with mortality and indicators of social deprivation. J Epidemiol Community Health. 1995;49(Suppl 2):S57-64.

27. Benzeval M. The self-reported health status of lone parents. Soc Sci Med. 1998;46(10):1337-1353.

28. Drever F, Doran T, Whitehead M. Exploring the relation between class, gender, and self rated general health using the new socioeconomic classification. A study using data from the 2001 census. J Epidemiol Community Health. 2004;58(7):590-596

29. Chandola T, Jenkinson C. The new UK National Statistics Socio-Economic Classification (NS-SEC); investigating social class differences in self-reported health status. J Public Health Med. 2000;22(2):182-190.

30. National Database for Primary Care Groups and Trust, National Primary Care Research and Development Centre. Available at: http://www.primary-care-db.org.uk, accessed 1 February 2008.

31. Walker A, O’Brien M, Traynor J, Fox K, Goddard E, Foster K. Living in Britain. Results from the 2001 general household survey. London: The Stationary Office; 2002.

32. Lloyd DC. Prescribing at the primary care group level: census data and prescribing indicators. J Clin Pharm Ther. 2001;26(2):93-101.

33. Quality and Outcomes Framework 2004-2005. NHS Information Centre. Available at: http://www.ic.nhs.uk/statistics-anddata-collections/qof-information/qof-2004-05, accessed 11 November 2007

34. South East Public Health Observatory. Available at: http://www.sepho.org.uk, accessed 20 January 2008

35. Pearce N. The ecological fallacy strikes back. J Epidemiol Community Health. 2000;54(5):326-327.

36. Strong M, Maheswaran R, Pearson T. A comparison of methods for calculating general practice level socioeconomic deprivation. Int J Health Geogr. 2006;5:29.

37. Rogers A, Pilgrim D, Brennan S, Sulaiman I, Watson G, Chew-Graham C. Prescribing benzodiazepines in general practice: a new view of an old problem. Health (London). 2007;11(2):181-198.

38. Rothera I, Jones R, Gordon C. An examination of the attitudes and practice of general practitioners in the diagnosis and treatment of depression in older people. Int J Geriatr Psychiatry. 2002;17(4):354-358.

39. Butler R, Collins E, Katona C, Orrell M. How do general practitioners select antidepressants for depressed elderly people? Int J Geriatr Psychiatry. 2000;15(7):610-613.

40. Kirmayer LJ. Cultural variations in the clinical presentation of depression and anxiety: implications for diagnosis and treatment. J Clin Psychiatry. 2001;62(Suppl 13):22-28.

41. Docherty JP. Barriers to the diagnosis of depression in primary care. J Clin Psychiatry. 1997;58(Suppl 1):5-10.

42. Mensah SA, Beavis JM, Thapar AK, Kerr M. The presence and clinical implications of depression in a community population of adults with epilepsy. Epilepsy Behav. 2006;8(1):213-219. 


\begin{tabular}{|c|c|c|c|c|}
\hline Predictor group & Category & Median † & Interquartile range & Range \\
\hline $\begin{array}{l}\text { Minor tranquiliser volume (average daily quantities (ADQs) per } 1,000 \text { specific } \\
\text { therapeutic group age-sex weightings prescribing unit (STAR-PU) }\end{array}$ & na & 9887.2 & $6794.2-14132.5$ & $109.2-134133.5$ \\
\hline Proportion of patients from south Asian ethnic group $A$ & $0 \%$ & 10470 & $7386.3-14218.2$ & $135.2-49051.5$ \\
\hline Proportion of patients from south Asian ethnic group B & $>0$ and $<=2 \%$ & 10380.0 & $7392.0-14565.5$ & $234.3-71524.4$ \\
\hline Proportion of patients from south Asian ethnic group C & $>2$ and $<=10 \%$ & 9428.6 & $6313.7-13744.1$ & $110.14-134133.5$ \\
\hline Proportion of patients from south Asian ethnic group $D$ & $>10 \%$ & 8649.8 & $5228.8-13428.2$ & $109.2-114154.7$ \\
\hline Proportion of patients from black ethnic group $\mathrm{A}$ & $0 \%$ & 10746.9 & $7712.6-14492.2$ & $135.2-101664.5$ \\
\hline Proportion of patients from black ethnic group B & $>0$ and $<=2 \%$ & 10409.7 & $7367.3-14741.3$ & $110.1-114154.7$ \\
\hline Proportion of patients from black ethnic group C & $>2$ and $<=10 \%$ & 9005.6 & $5951.4-13313.4$ & $109.2-134133.5$ \\
\hline Proportion of patients from black ethnic group $D$ & $>10 \%$ & 6525.7 & $4075.6-9954.9$ & $119.7-64681.8$ \\
\hline Unadjusted disease prevalence: mental health $\mathrm{A}$ & $<=0.5 \%$ & 9552.0 & $6602.2-13752.2$ & $110.1-101644.5$ \\
\hline Unadjusted disease prevalence: mental health B & $>0.5 \%$ and $<=1 \%$ & 10023.6 & $6767.1-141779$ & $218.5-114154.7$ \\
\hline Unadjusted disease prevalence: mental health $\mathrm{C}$ & $>1 \%$ & 10857.1 & $7424.4-15936.3$ & $109.2-134133.5$ \\
\hline Unadjusted disease prevalence: epilepsy A & $<=0.5 \%$ & 8252.0 & $5449.2-11968.1$ & $109.2-114154.7$ \\
\hline Unadjusted disease prevalence: epilepsy B & $>0.5 \%$ and $<=1 \%$ & 10675.5 & $7634.8-14857.5$ & $234.3-134133.5$ \\
\hline Unadjusted disease prevalence: epilepsy C & $>1 \%$ & 14605.8 & $10240.1-21703.5$ & $2800.0-62908.1$ \\
\hline Index of Multiple Deprivation A & $<=10$ & 8355.2 & $6154.6-11037.0$ & $110.1-61846.1$ \\
\hline Index of Multiple Deprivation B & $>10$ and $<=20$ & 9203.2 & $6738.6-12450.9$ & $245.2-52785.6$ \\
\hline Index of Multiple Deprivation C & $>20$ and $<=40$ & 10655.7 & $70761.8-15026.5$ & $109.2-134133.5$ \\
\hline Index of Multiple Deprivation D & $>40$ & 12454.6 & $7632.6-17992.5$ & $119.7-101664.5$ \\
\hline Mean general practice GP age A & $<40$ & 8993.14 & $6104.6-13105.6$ & $466.6-40843.2$ \\
\hline Mean general practice GP age B & $>=40$ and $<50$ & 9565.4 & $6897.3-13179.8$ & $110.1-114154.7$ \\
\hline Mean general practice GP age C & $>=50$ and $<60$ & 10687.5 & $6983.5-15766.7$ & $109.2-134133.5$ \\
\hline Mean general practice GP age D & $>=60$ & 10843.3 & $6174.1-16772.0$ & $135.2-92836.8$ \\
\hline Proportion of list aged 75 or over $A$ & $<=5 \%$ & 8007.2 & $4876.6-13112.1$ & $110.1-134133.5$ \\
\hline Proportion of list aged 75 or over B & $>5 \%$ and $<=10 \%$ & 10200.2 & $7196.5-14384.7$ & $109.2-114154.7$ \\
\hline Proportion of list aged 75 or over $\mathrm{C}$ & $>10 \%$ & 10947.3 & $8100.1-14344.4$ & $496.4-51281.4$ \\
\hline Single-handed practices & & 10663.7 & $6213.0-16441.2$ & $119.7-16441.2$ \\
\hline Group practices & & 9715.4 & $6932.5-13576.5$ & $109.2-134133.5$ \\
\hline Training practices & & 9019.8 & $6586.1-12236.1$ & $109.2-45207.2$ \\
\hline Non-training practices & & 10317.1 & $6903-14917.5$ & $110.1-134133.5$ \\
\hline
\end{tabular}




\begin{tabular}{|c|c|c|c|c|c|c|}
\hline Predictor group & Category & B coefficient & $\begin{array}{r}\text { Back transformed } \\
\text { change factor } \\
(10)\end{array}$ & $\begin{array}{r}\text { Prescribing } \\
\text { change }\end{array}$ & $\begin{array}{r}95 \% \text { Confidence } \\
\text { interval }\end{array}$ & $\begin{array}{r}\text { Back transformed } \\
95 \% \text { confidence } \\
\text { interval }\end{array}$ \\
\hline Proportion of patients from south Asian ethnic group $A$ & $0 \%$ & \multicolumn{5}{|l|}{ Baseline comparator } \\
\hline Proportion of patients from south Asian ethnic group B & $>0$ and $<=2 \%$ & 0.017 & 1.040 & 245.7 & $0.000-0.034$ & $1.0-1.082$ \\
\hline Proportion of patients from south Asian ethnic group C & $>2$ and $<=10 \%$ & 0.039 & 1.094 & 574.8 & $0.017-0.060$ & $1.041-1.149$ \\
\hline Proportion of patients from south Asian ethnic group $D$ & $>10 \%$ & -0.004 & 0.991 & -52.7 & $-0.030-0.023$ & $0.933-1.054$ \\
\hline Proportion of patients from black ethnic group $A$ & $0 \%$ & \multicolumn{5}{|l|}{ Baseline comparator } \\
\hline Proportion of patients from black ethnic group B & $>0$ and $<=2 \%$ & -0.022 & 0.951 & -300.4 & $-0.036--0.008$ & $0.921-0.982$ \\
\hline Proportion of patients from black ethnic group C & $>2$ and $<=10 \%$ & -0.115 & 0.767 & -1429.7 & $-0.138--0.093$ & $0.728-0.808$ \\
\hline Proportion of patients from black ethnic group $D$ & $>10 \%$ & -0.253 & 0.558 & -2707.9 & $-0.284--0.093$ & $0.519-0.599$ \\
\hline Unadjusted disease prevalence: mental health $\mathrm{A}$ & $<=0.5 \%$ & \multicolumn{5}{|l|}{ Baseline comparator } \\
\hline Unadjusted disease prevalence: mental health B & $>0.5 \%$ and $<=1 \%$ & 0.013 & 1.031 & 191.2 & $0.002-0.025$ & $1.004-1.059$ \\
\hline Unadjusted disease prevalence: mental health C & $>1 \%$ & 0.040 & 1.095 & 583.3 & $0.020-0.059$ & $1.046-1.147$ \\
\hline Unadjusted disease prevalence: epilepsy A & $<=0.5 \%$ & \multicolumn{5}{|l|}{ Baseline comparator } \\
\hline Unadjusted disease prevalence: epilepsy B & $>0.5 \%$ and $<=1 \%$ & 0.065 & 1.161 & 985.9 & $0.051-0.078$ & $1.126-1.197$ \\
\hline Unadjusted disease prevalence: epilepsy C & $>1 \%$ & 0.150 & 1.413 & 2531.0 & $0.116-0.184$ & $1.307-1.528$ \\
\hline Index of Multiple Deprivation A & $<=10$ & \multicolumn{5}{|l|}{ Baseline comparator } \\
\hline Index of Multiple Deprivation B & $>10$ and $<=20$ & 0.044 & 1.107 & 655.4 & $0.030-0.059$ & $1.071-1.144$ \\
\hline Index of Multiple Deprivation C & $>20$ and $<=40$ & 0.120 & 1.319 & 1956.8 & $0.104-0.136$ & $1.272-1.369$ \\
\hline Index of Multiple Deprivation D & $>40$ & 0.185 & 1.532 & 3260.9 & $0.166-0.205$ & $1.466-1.602$ \\
\hline Mean general practice GP age A & $<40$ & \multicolumn{5}{|l|}{ Baseline comparator } \\
\hline Mean general practice GP age B & $>=40$ and $<50$ & 0.027 & 1.064 & 394.0 & $0.008-0.046$ & $1.019-1.111$ \\
\hline Mean general practice GP age C & $>=50$ and $<60$ & 0.066 & 1.164 & 1005.5 & $0.045-0.088$ & $1.108-1.225$ \\
\hline Mean general practice GP age D & $>=60$ & 0.074 & 1.186 & 1142.2 & $0.043-0.105$ & $1.105-1.274$ \\
\hline Proportion of list aged 75 or over $\mathrm{A}$ & $<=5 \%$ & \multicolumn{5}{|l|}{ Baseline comparator } \\
\hline Proportion of list aged 75 or over B & $>5 \%$ and $<=10 \%$ & 0.071 & 1.178 & 1092.0 & $0.054-0.888$ & $1.131-1.227$ \\
\hline Proportion of list aged 75 or over $C$ & $>10 \%$ & 0.092 & 1.236 & 1444.5 & $0.070-0.113$ & $1.176-1.298$ \\
\hline Group practice & & \multicolumn{5}{|l|}{ Baseline comparator } \\
\hline Single-handed practice & & -0.008 & 0.982 & -111.5 & $-0.026-0.010$ & $0.943-1.022$ \\
\hline Non-training practice & & \multicolumn{5}{|l|}{ Baseline comparator } \\
\hline Training practice & & -0.047 & 0.897 & -631.7 & $-0.059--0.036$ & $0.873-0.921$ \\
\hline Constant & & 3.787 & 6127.13 & & $3.756-3.818$ & $5705.0-6580.6$ \\
\hline
\end{tabular}

